curriculum. I will not argue here the wide question whether these sciences should be included in the education of every gentleman. I am inclined to think they should. The physician must know something of them. It would be just as easy, I think easier, to teach them to an intelligent boy, whose mind is plastic and eminently capable of receiving and retaining impressions, as to a man past the age of eighteen or twenty. One who can be taught to read the dead languages as fluently as English, can surely be instructed in the compositions of material things and their methods of change, in the varying construction and special characters of living beings, vegetable or animal. It may be said that the means of such instruction are wanting; but that is a matter of detail with which $I$ have no business at present. It would immensely simplify the labour of medical teachers if the young men who come to their schools were already versed in Botany, Chemistry, and Natural History. I can see no reason why they should not be so. With the soil thus favourably prepared for further cultivation, we could direct ourselves more singly to the work of inculcating that long and complex history of disease and its cure, the study of which is quite sufficient to occupy any man during the three short years which are allotted to his medical studies. Not being called upon to attend lectures on Botany or Chemistry, the student would have no reason to complain of being overworked, and would have more time to devote himself to those practical studies in the hospital which are by far the most important part of his medical education. I cannot, of course, include Human Anatomy among the sciences which can be taught the youth in the earlier training; for its study requires appliances which can only be met with in medical schools, and is of so serious, I might say so sacred, a nature, that it seems fitter for grown men. I must relegate, also, to the later training the science of Human Physiology, which depends, almost as much as Anatomy, on the lessons of the dissecting room.

(To be concladed.)

\section{ACUTE PROSTATITIS; ACUTE MANIA.}

\section{Br W. J. M A R S H,} ASSISTANT YEDICAL OFFICER, OXON AND BERKS COLNTIES ASYLTIT,
LITILEMORE.

\section{ACUTE PROSTATITIS}

J. P_- aged eighty, a healthy, able-bodied imbecile in the Littlemore Asylum, complained of retention of urine, with dribbling, on the 12th January. Mr. Hussey succeeded in partially relieving him by the catheter on two occasions, and the man passed by his own efforts from one to two pints every twenty-four hours. Death occurred on the 23rd, after a few hours' delirium, the result of exhaustion from want of rest, consequent on the frequent and anxious desire for micturition.

Upon post-mortem examination by Mr. Hussey, the whole of the prostate was found very much enlarged, and section showed that the enlargement was quite recent, and not chronic, as is usual in such cases. It was, in fact, a case of simple plastic inflammation. The bladder and urine were perfectly healthy. Severe cases of prostatic and strictural obstruction often require almost immediate relief. Expectancy, and so-called "palliatives"- whatever they may be,-will rarely afford this. In the event of the catheter from any reason proving useless or dangerous, unless there is well-marked hopeless exhaustion or approaching dissolution, the question of tapping the bladder should receive more serious attention than it generally does. We make no great difficulty about the analogous but rather more dangerous operation for dropsy. It is not my intention to be didactic on the subject. The uninformed and sceptical can see and read the practice of the best authorities of the day. The indifferent routinist and rash enthusiast will not be made equal to the emergency by any amount of talk. Doubtless, there are two sides to the question. I only urge those readers of THE LANCET whom it may concern (and how few, particularly in the country, does it not concern) to learn and consider for themselves. These remarks do not apply to the above case. There were reasons, deemed by excellent authority to be sufficient, contra-indicating further interference.

\section{ACUTE MANIA.}

C. M- a strong, healthy young woman, was admitted into the Littlemore Asylum on the 15th January, in a state of acute mania. She was noisy, violent, destructive, and feverish. Small doses of morphia and tartrate of antimony being of no avail, a grain of muriate of morphia was given twice, and sometimes three times a day, for several days, under which she has rapidly improved. The dose is now often omitted, but, if not resumed in sufficient time, a marked tendency to relapse is the result. On no occasion, in the abore case, has headache, dry mouth, or sickness been complained of or observed.

Many have been thus saved from a tedious and perhaps incurable career of insanity by timely and efficient sedative treatment; and muriate of morphia is undoubtedly the best sedative for such cases, hydrate of chloral not excepted. The "alterative" or mercurial treatment of acute cerebromental disorder is much, and to a certain extent deservedly, extolled; but in the majority of cases it is uncertain and tedious, as compared with the sedative treatment by morphia. The remote prospect of undue narcosis in such cases, from the treatment advocated, does not call for much discussion here. Practical medicine is guided, not limited, by physiological and chemical research. Itwould be mere dogma to lay down precisely the conditions which contraindicate the sedative treatment of acute cerebro-mental disorder by grain doses of muriate of morphia. The pupils are sometimes very contracted, as in many cases of acute paralytic dementia, and yet a grain of muriate of morphia may be given, and perhaps repeated more than once, at intervals of from four to eight hours or less, with marked benefit. Again, an apparent tendency to renal dropsy might, but by no means of necessity, contraindicate the treatment suggested. Intelligence, caution, and vigilance are necessary, as they always are in the proper treatment of disease, but not exceptionally so; and much must be left to the experience and judgment of the physician in the adoption or rejection of therapeutics.

Littlemore, January $29 \mathrm{th}, 1870$.

\section{THE HYDRATE OF CHIORAL.}

\section{By J. FREDERICK PLOMLEY, M.R.C.P. EDIN., \&c.}

Doring the past few weeks I have administered the chloral hydrate on several occasions, and with marked success. Given as a hypnotic, I have found it a much surer producer of sleep than opium or any of its preparations. Another thing greatly in its favour is that (so far as $\mathrm{my}$ experience has gone) it is without the unpleasant aftereffects of opium-e. g., constipation, loss of appetite, \&c. Two of the patients to whom this salt was administered complained of severe headache when first awaking in the morning; but I attributed this, in the one case, to the large quantity of chlorodyne which had been taken a few hours previously for the purpose of allaying pain and inducing sleep, and, in the other, to a cause quite apart from any effect the medicine might have had. In one other case a feeling of intoxication was complained of when first awaking, but this soon passed off.

The first patient to whom I gave the chloral was a gentleman who has been for many years a great sufferer from rheumatic gout, and who has been in the habit of taking almost every night a large dose of opium in one form or another for the purpose of easing his suffering and procuring sleep. As a consequence of this no small amount of gastric disturbance has resulted. He now takes forty-five grains of the chloral hydrate in place of the opium, and, within ten minutes after doing so, he falls into a sound sleep, which lasts from ten to twelve hours, and awakes in the morning refreshed and with an entire absence of all the unpleasant symptoms of gastric derangement from which he has so long suffered.

In another case, that of a young girl who for some years past has been a great sufferer from bronchitic asthma, the paroxysms of which, occurring every night, have been very severe, and quite prevented sleep, a half-drachm dose of 